\title{
The effect of anesthetic techniques on neutrophil to lymphocyte ratio in patients undergoing infraumbilical surgeries
}

\author{
Nethra Surhonne, Chaithali Hebri, Sudheesh Kannan, \\ Devika Rani Duggappa, Raghavendra Rao RS, and Chethana G Mapari \\ Department of Anesthesiology, Victoria Hospital, Bangalore Medical College and Research Institute, Bangalore, \\ India
}

\begin{abstract}
Background: Neutrophil to lymphocyte ratio (NLR) is a simple marker in peripheral blood and is used to assess inflammatory response and physiological stress during the peri-operative period. Anesthetic technique may influence NLR, thereby modulating the inflammatory response and surgical outcomes. The study aimed to evaluate the relationship between blood NLR and anesthetic techniques in patients undergoing infraumbilical surgeries.

Methods: Institutional ethical committee approval and patient consent were obtained. A prospective randomized double-blinded study was conducted between July 2017 and November 2017, involving 80 patients classified as the American Society of Anesthesiologists grade 1 and 2, aged 18-60 years, and scheduled for elective infraumbilical surgeries. Unwilling and those with infections were excluded. The patients were randomly divided into two groups: Group G (general anesthesia) and Group S (spinal anesthesia) as per the standardized protocol. Differential counts of leukocytes and NLR in the peripheral blood were obtained pre-operatively on the morning of surgery and at $2 \mathrm{~h}$ and $24 \mathrm{~h}$ after surgery in both the groups. The data were analyzed using appropriate statistical tests.

Results: The demographic parameters, basal total leukocyte count (TLC), and NLR were comparable between the groups. TLC and NLR were significantly higher in Group G as compared to that in Group S post-operatively. The post-operative rise in TLC and NLR from the basal values was significantly higher in Group G as compared to that in Group S.

Conclusions: General anesthesia was associated with a greater increase in TLC and NLR when compared with spinal anesthesia.
\end{abstract}

Keywords: General anesthesia; Lymphocytes; Neutrophils; Neutrophil lymphocyte ratio; Spinal anesthesia.

Corresponding author: Sudheesh Kannan, M.D.

Department of Anesthesiology, Victoria Hospital, Bangalore Medical College and Research Institute, Fort, K R Road, Bangalore, Karnataka 560002, India

Tel: +91-9900134694, Fax: +91-80-26704347, Email: drsudhi@rediffmail.com

ORCID: https://orcid.org/0000-0002-3341-538X

This work was presented at ISACON-2016, National Conference of Indian Society of Anaesthesiologists, November 2016, Punjab Agricultural University, Ludhiana, India.

Received: January 18, 2019. Revised: March 28, 2019. Accepted: May 16, 2019.

Korean J Anesthesiol 2019 October 72(5): 458-465

https://doi.org/10.4097/kja.d.19.00022

(c) This is an open-access article distributed under the terms of the Creative Commons Attribution Non-Commercial License (http://creativecommons.org/ licenses/by-nc/4.0/), which permits unrestricted non-commercial use, distribution, and reproduction in any medium, provided the original work is properly cited. 


\section{Introduction}

The neuroendocrine system is activated during anesthesia and surgery resulting in the release of neuroendocrine hormones and cytokines [1-3]. Systemic leukocytic alterations, including leukocytosis, neutrophilia, and lymphopenia may occur in response to surgery by various hormones, cytokines, and acute-phase reactants; apoptosis of lymphocytes; or inhibition of apoptosis of neutrophils [4,5]. During anesthesia and surgery, there are changes in every stage of the immune system secondary to the changes in the general physiological response, which are linked to the extent of surgery, age of the patient, general health conditions, medications used, and blood transfusions (if performed). There are various investigations for assessing the neuroendocrine response, such as interleukin measurements (IL-6, TNF- $\alpha$ ), cortisol levels, C-reactive protein (CRP), and leptin levels; however, these investigations are expensive.

Neutrophil to lymphocyte ratio (NLR) is a simple and inexpensive marker of inflammatory response and can provide the relationship between the inflammatory environment and physiological stress [6]. NLR has been found to be a simple predictor of outcomes in patients with cancers and patients with stable coronary artery disease $[7,8]$. NLR is not only affected by surgical trauma but also by the anesthetic method [6,9]. The normal NLR is found to vary across different populations from $1.65 \pm$ 0.79 to $2.8 \pm 1.6[10,11]$. The effects of neuroendocrine changes induced by different anesthetic techniques could influence NLR but the effect remains largely unknown. Very few studies have been conducted to evaluate the effects of general and spinal anesthesia on NLR [6]. Therefore, this study was conducted to evaluate the effects of different anesthetic techniques on NLR.

\section{Materials and Methods}

After obtaining approval from the ethical committee (BMCRI/PS/56/2017-18 dated: 06.07.2017) and informed written consent from the patients, a prospective double-blind randomized-controlled study was conducted involving 80 patients aged 18-60 years, classified the American Society of the Anesthesiologists grade I and II, and who were scheduled for elective open infraumbilical surgeries from July 2017 to November 2017. The study was enrolled in the Clinical Trials Registry - India (CTRI/2018/05/013826).

Patients with existing acute infections, morbid obesity; patients on chronic treatment with steroids or immunosuppressants, patients on recent chemotherapy; patients with endocrine diseases, electrolyte imbalance, hepatic and renal dysfunctions; chronic alcohol abusers; and patients with a history of undertaking surgery that lasted for $>90$ min were excluded from the study. The patients were randomly allocated to one of the two groups using random numbers generated from www.random. org: Group G received general anesthesia, and Group S received spinal anesthesia for infraumbilical surgeries. Allocation concealment was ensured using sequentially numbered sealed envelopes which were opened after shifting the patients to the operation table.

All patients were assessed pre-operatively and informed thoroughly about both the techniques of anesthesia and their risks and benefits. The patients were kept fasting for $8 \mathrm{~h}$ before surgery. Alprazolam $0.5 \mathrm{mg}$ and ranitidine $150 \mathrm{mg}$ were administered orally on the previous night of surgery. Pre-operative hemoglobin level, total count, differential count, and NLR were evaluated apart from other necessary investigations. On the day of surgery, intravenous (IV) access was established and IV Ringer lactate infusion was started. Once the sealed envelopes were opened, the patients were informed about the anesthesia they would be receiving, and they were given choices to opt out of the study if they were not happy with the anesthesia technique. Routine standard of care was planned for patients who opted out of the study.

In group $\mathrm{G}$, monitoring included electrocardiography (ECG), peripheral oxygen saturation $\left(\mathrm{SpO}_{2}\right)$, non-invasive blood pressure (NIBP), end-tidal carbon dioxide, and train of four (TOF). The monitors were connected to the patients, and the baseline hemodynamic parameters were recorded. The patients were premedicated with glycopyrrolate $10 \mu \mathrm{g} / \mathrm{kg}$, midazolam 0.03 $\mathrm{mg} / \mathrm{kg}$, and fentanyl $2 \mu \mathrm{g} / \mathrm{kg}$ and were pre-oxygenated for $3 \mathrm{~min}$. The patients were induced with propofol $(2 \mathrm{mg} / \mathrm{kg})$ IV followed by vecuronium $0.1 \mathrm{mg} / \mathrm{kg}$ IV. After $3 \mathrm{~min}$, intubation was performed with an appropriate-sized endotracheal tube. Anesthesia was maintained with $33 \%$ oxygen in $66 \%$ nitrous oxide and $1-2 \%$ isoflurane, which was titrated to maintain the hemodynamic parameters within $20 \%$ of the basal readings. Adequate muscle relaxation was ensured by maintaining the TOF count $<2$ with intermittent injections of vecuronium $(0.02 \mathrm{mg} / \mathrm{kg})$. At the end of the surgery, muscle relaxation was reversed with glycopyrrolate $10 \mu \mathrm{g} / \mathrm{kg}$ and neostigmine $0.05 \mathrm{mg} / \mathrm{kg} \mathrm{IV}$, and the patients were extubated when the TOF ratio became $>0.9$.

In group $\mathrm{S}, \mathrm{ECG}, \mathrm{NIBP}$, and $\mathrm{SpO}_{2}$ monitors were connected and the baseline hemodynamic parameters were recorded. An intravenous line was started using 18 G IV cannula through which $500 \mathrm{ml}$ of Ringers lactate solution was infused and midazolam $0.03 \mathrm{mg} / \mathrm{kg}$ was administered IV before administration of spinal anesthesia. Using a $25 \mathrm{G}$ spinal needle, lumbar puncture was performed between L2-L3 or L3-L4 intervertebral space. After confirming the free flow of cerebrospinal fluid, $0.5 \%$ hyperbaric bupivacaine $(12.5 \mathrm{mg}$ ) was injected into the space.

Hemodynamic parameters (heart rate, systolic blood pressure, diastolic blood pressure, mean arterial pressure, and $\mathrm{SpO}_{2}$ ) were continuously monitored and recorded every $5 \mathrm{~min}$ till the 
end of surgery in both the groups. Intraoperative fluid management was guided by hemodynamic changes and intraoperative blood loss. Post-operatively, intravenous fluids, antibiotics, and other drugs were administered as per the standard institutional protocol. The pain was treated with paracetamol $1 \mathrm{~g}$ intravenous infusion every $6 \mathrm{~h}$. Tramadol $50 \mathrm{mg}$ IV was administered as a rescue analgesic if the pain persisted even after paracetamol administration. Post-operative nausea and vomiting were managed by administration of ondansetron $4 \mathrm{mg}$ IV. Blood samples were collected from the antecubital vein pre-operatively on the morning of surgery and then at $2 \mathrm{~h}$ and $24 \mathrm{~h}$ after surgery. Neutrophil and lymphocyte counts were derived from differential percentages of leukocytes measured by automatic cell counters. The calculation of NLR was entrusted to one of the anesthesiologists who was blinded to the study groups. The anesthesiologist administering anesthesia to the subjects was unaware of the baseline or follow up values of the blood counts and NLR.

The sample size was calculated based on a previous study. We hypothesized that NLR would be lower in patients receiving spinal anesthesia as compared to general anesthesia. Keeping two-tailed type I ( $\alpha$ ) error at 0.05 , at least 36 patients in each group were required to detect a minimum difference of 1 in NLR between the two groups with a power of $80 \%$, assuming a standard deviation of 1.5 and NLR under general anesthesia to be 10 (based on the previous study). We enrolled 40 patients in each group to compensate for the dropouts.

The data were entered into a Microsoft excel datasheet and were analyzed using SPSS 22 version software (IBM SPSS Statistics for Windows version 22, IBM Corp., USA). Shapiro-Wilk test was applied to assess normalilty of the distribution of continuous variables. The categorical data are expressed as frequencies, and the continuous and discrete variables as mean \pm SD or median (interquartile range, IQR). Chi-square test and Fisher-exact test were used for comparing the categorical data. Independent sample $t$-test and Mann Whitney $U$ test were applied for continuous data with normal and skewed distribution, respectively. Paired $t$-test was used for intragroup comparison of normally distributed data, whereas the skewed data were compared using the Wilcoxon sign rank test. A P value of $<0.05$ was considered significant.

\section{Results}

Eighty patients were included in the study (CONSORT

Table 1. Demographic Characteristics and Surgical Parameters of the Included Patients

\begin{tabular}{lccc}
\hline \multicolumn{1}{c}{ Parameters } & $\begin{array}{c}\text { Group G } \\
(\mathrm{n}=40)\end{array}$ & $\begin{array}{c}\text { Group S } \\
(\mathrm{n}=40)\end{array}$ & P value \\
\hline Age (yr) & $40.1 \pm 9.8$ & $41.7 \pm 10.4$ & 0.495 \\
Gender (M/F) & $19 / 21$ & $25 / 15$ & 0.177 \\
Weight (kg) & $63.0 \pm 6.6$ & $63.8 \pm 7.3$ & 0.608 \\
Height (cm) & $156.8 \pm 12.2$ & $160.2 \pm 13.4$ & 0.225 \\
ASA grade (I : II) & $22: 18$ & $21: 19$ & 0.822 \\
Duration of surgery (min) & $46.5 \pm 13.8$ & $41.7 \pm 11.5$ & 0.098 \\
Type of surgery & & & \\
$\quad$ Unilateral inguinal & 7 & 15 & 0.252 \\
$\quad$ hernia & & & \\
$\quad$ Bilateral inguinal hernia & 3 & 6 & \\
Incisional hernia & 10 & 4 & \\
$\quad \begin{array}{l}\text { Umbilical hernia } \\
\text { Open interval } \\
\text { appendicectomy }\end{array}$ & 12 & 7 & \\
$\quad$ Gynaecological surgeries & 4 & 4 & \\
\hline
\end{tabular}

Values are presented as mean \pm SD or number of patients.

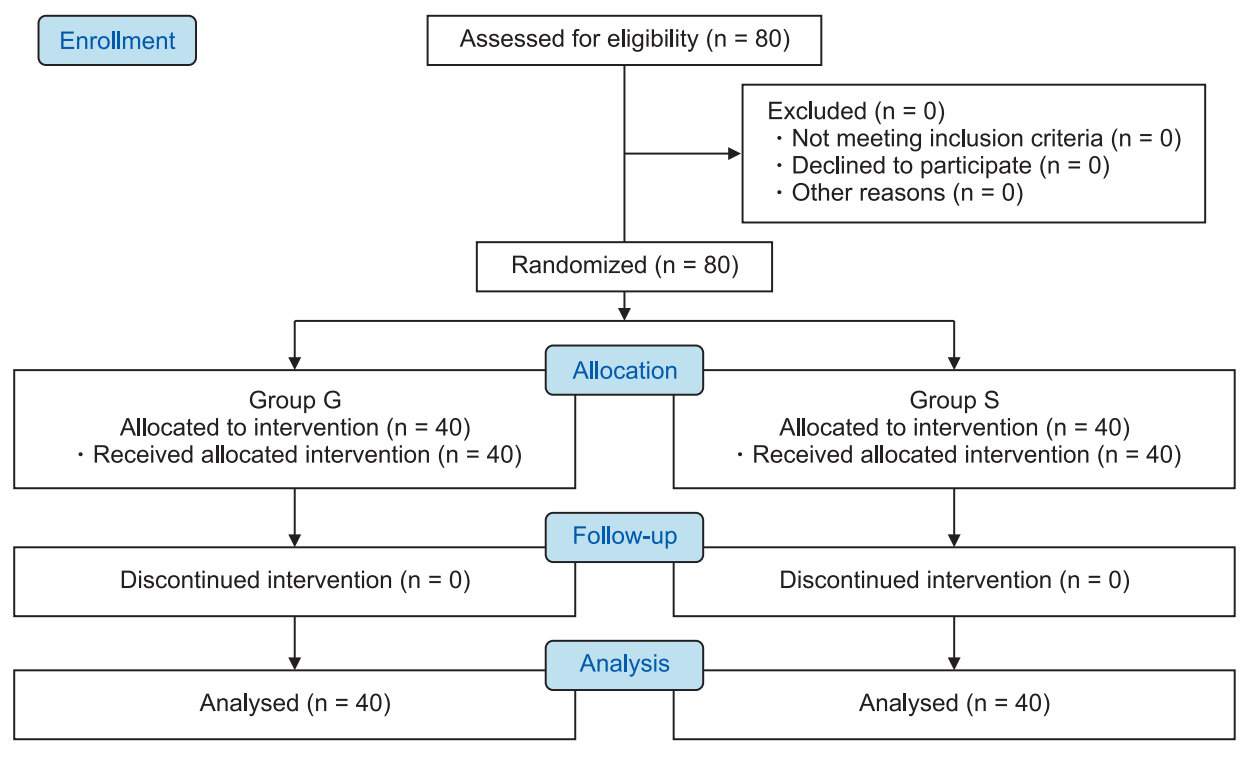

Fig. 1. CONSORT flow diagram. 
flow-diagram, Fig. 1). There were no dropouts. The demographic characteristics, duration of surgery and the type of surgeries in both the groups were comparable at baseline (Table 1). The maximum level of sensory block attained in Group S was between $\mathrm{T} 6$ and $\mathrm{T} 8$ in most of the patients (T4 in 7 patients, T6 in 17 patients, T8 in 12 patients, and T10 in 4 patients). The total leukocyte count (TLC) was comparable between both the groups at baseline and it increased post-operatively in both the groups. The intergroup comparison showed a significantly higher TLC in group G as compared to that in Group S at $2 \mathrm{~h}$, but not at $24 \mathrm{~h}$ post-surgery (Table 2). The median (IQR) increase in TLC from the baseline in group G was 600 (300-3325) cells/

Table 2. Total Leukocyte Count and Neutrophil to Lymphocyte Ratio in the Both Groups

\begin{tabular}{|c|c|c|c|}
\hline Parameter & Group G & Group S & $P$ value \\
\hline Pre-operative total leukocyte count (cells/cu mm) & $\begin{array}{l}9017.25 \pm 2873.96 \\
(8098.11-9936.38)\end{array}$ & $\begin{array}{r}9048.25 \pm 2450.62 \\
(8264.5-9831.99)\end{array}$ & $0.959^{*}$ \\
\hline Post-operative total leukocyte count at $2 \mathrm{~h}$ (cells/cu mm) & $\begin{array}{c}10616.75 \pm 3409.35 \\
(9526.38-11707.11)\end{array}$ & $\begin{array}{l}9172.25 \pm 2314.8 \\
(8431.93-9912.56)\end{array}$ & $0.032^{*}$ \\
\hline Post-operative total leukocyte count at $24 \mathrm{~h}$ (cells/cu mm) & $\begin{array}{c}10792 \pm 2939.63 \\
(9851.86-11732.13)\end{array}$ & $\begin{array}{l}9652.75 \pm 2408.09 \\
(8882.6-10422.89)\end{array}$ & $0.062^{*}$ \\
\hline Pre-operative NLR & $2.71 \pm 1.46(2.24-3.17)$ & $2.90 \pm 0.99(2.58-3.21)$ & $0.501^{\dagger}$ \\
\hline NLR at $2 \mathrm{~h}$ (median [IQR]) $(95 \% \mathrm{CI})$ & $\begin{array}{c}7[5.51-10.75] \\
(6.85-9.68)\end{array}$ & $\begin{array}{c}3[2.79-4.16] \\
(3.24-3.91)\end{array}$ & $<0.001^{\ddagger}$ \\
\hline NLR at $24 \mathrm{~h}$ (median [IQR]) (95\% CI) & $\begin{array}{r}6[5.03-8.6] \\
(6.15-7.99)\end{array}$ & $\begin{array}{c}3[2.72-3.9] \\
(3.19-4.18)\end{array}$ & $<0.001^{\ddagger}$ \\
\hline
\end{tabular}

Values are presented as mean \pm SD (95\% CI) or median (IQR) (95\% CI). NLR: neutrophil to lymphocyte ratio. ${ }^{*}$ Independent sample $t$-test, ${ }^{\dagger}$ Independent sample $t$-test applied after $\log$ transformation, ${ }^{\ddagger}$ Mann Whitney $U$ test.

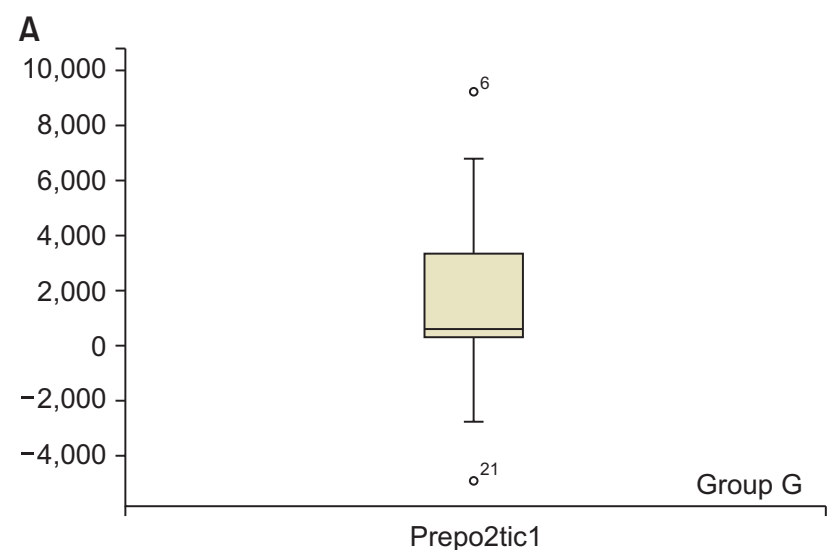

B

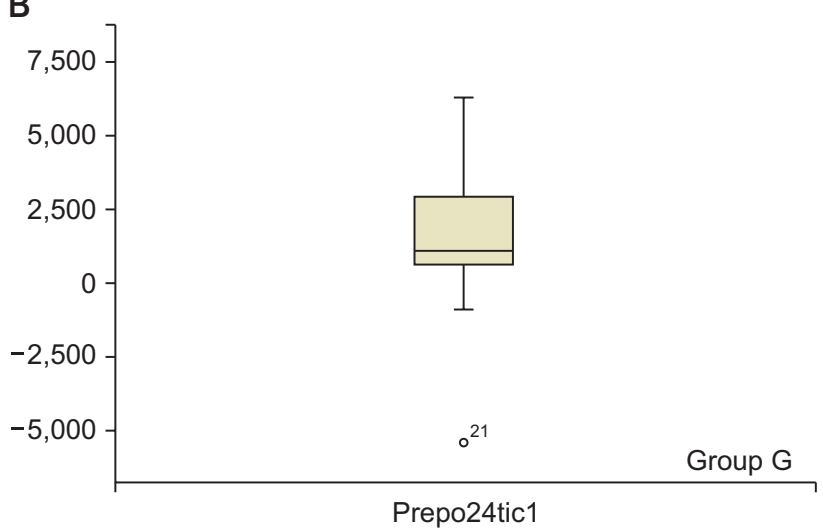

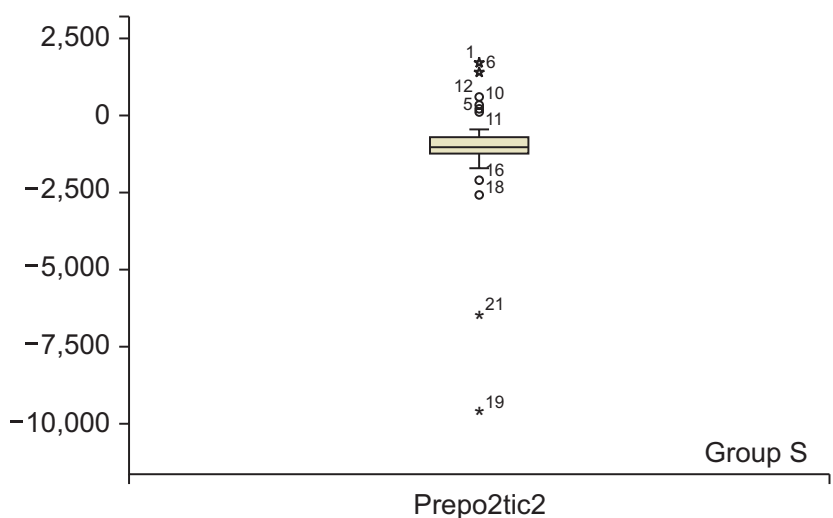

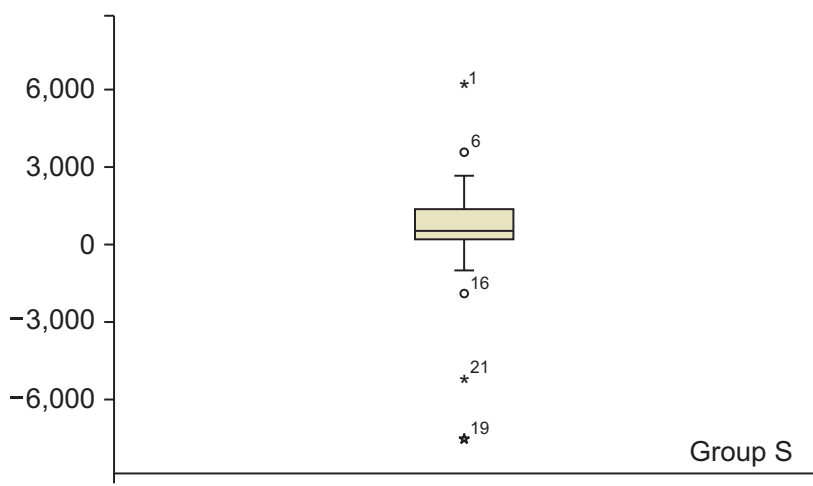

Prepo24tic2

Fig. 2. (A) Distribution of difference in total leukocyte count at $2 \mathrm{~h}$ from the basal value in Group $\mathrm{G}$ and Group S. (B) Distribution of difference in total leukocyte count at $24 \mathrm{~h}$ from the basal value in Group $\mathrm{G}$ and Group S. 
$\mathrm{cu} \mathrm{mm}(\mathrm{P}=0.001)$ at $2 \mathrm{~h}$ and $1100(600-2875)$ cells/cu mm $(\mathrm{P}=0.001)$ at $24 \mathrm{~h}$, which were both clinically and statistically significant. In group $\mathrm{S}$, the median (IQR) increase in TLC from the baseline was $300(100-625)$ cells/cu mm $(\mathrm{P}=0.682)$ at $2 \mathrm{~h}$ and $535(200-1250)$ cells/cu $\mathrm{mm}(\mathrm{P}=0.073)$ at $24 \mathrm{~h}$, which were both clinically and statistically not significant. The changes in TLC were significantly higher in Group $G$ as compared to that in Group $\mathrm{S}$ at $2 \mathrm{~h}(\mathrm{P}=0.002)$ (Fig. $2 \mathrm{~A})$ and $24 \mathrm{~h}(\mathrm{P}=0.002)$ post-surgery (Fig. 2B).

The baseline NLR was comparable in both the groups at baseline, and it increased in both the groups post-operatively. The NLR was significantly higher in group $G$ as compared to that in Group $\mathrm{S}$ at $2 \mathrm{~h}$ and $24 \mathrm{~h}$ post-surgery (Table 2). The median (IQR) increase in NLR from the baseline was 5 (2.73-7.16) $(\mathrm{P}<0.001)$ at $2 \mathrm{~h}$ and $4(2.59-6.05)(\mathrm{P}<0.001)$ at $24 \mathrm{~h}$ in group $\mathrm{G}$, which were both clinically and statistically significant. The median (IQR) increase in NLR from the baseline was $1(0.24-$ $0.94)(\mathrm{P}<0.001)$ at $2 \mathrm{~h}$ and $0(0.13-1.01)(\mathrm{P}=0.002)$ at $24 \mathrm{~h}$ in group $\mathrm{S}$, which were clinically not significant. The magnitude of change in NLR was significantly higher in Group $G$ as compared to that in Group $S$ at $2 \mathrm{~h}(\mathrm{P}<0.001)($ Fig. $3 \mathrm{~A})$ and $24 \mathrm{~h}(\mathrm{P}<0.001)$
(Fig. 3B).

There was no significant change in the hemoglobin levels in the pre- and post-operative periods in both groups (Fig. 4). The median (IQR) changes in hemoglobin level from the baseline were $0.4 \%(0.2-0.625)(\mathrm{P}=0.001)$ at $2 \mathrm{~h}$ and $0.45 \%(0.2-1.0)$

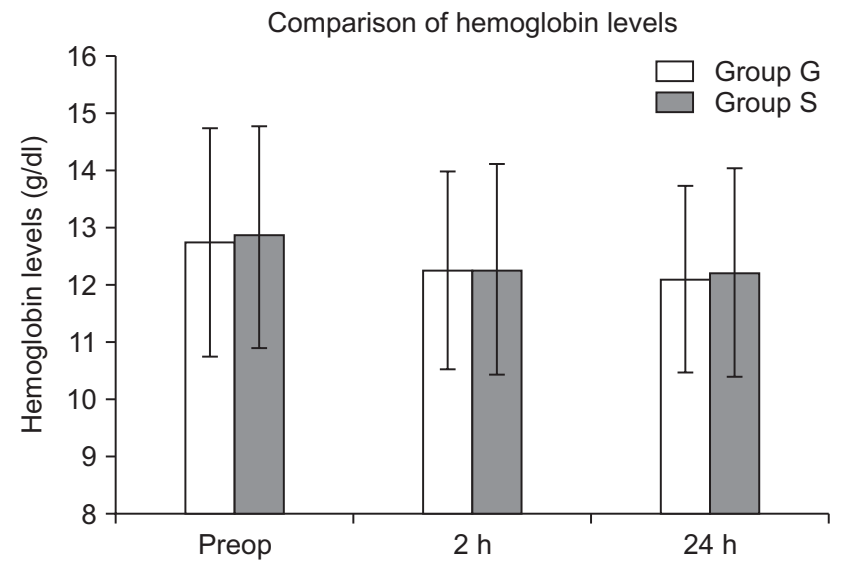

Fig. 4. Comparison of hemoglobin levels between the two groups.

A
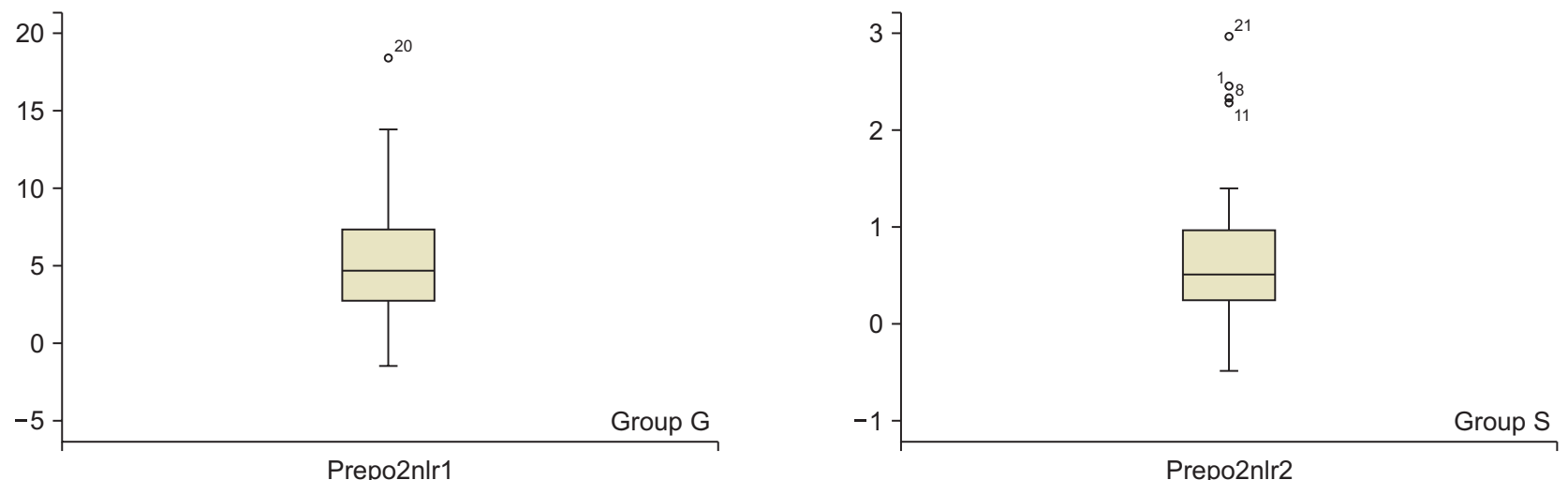

B
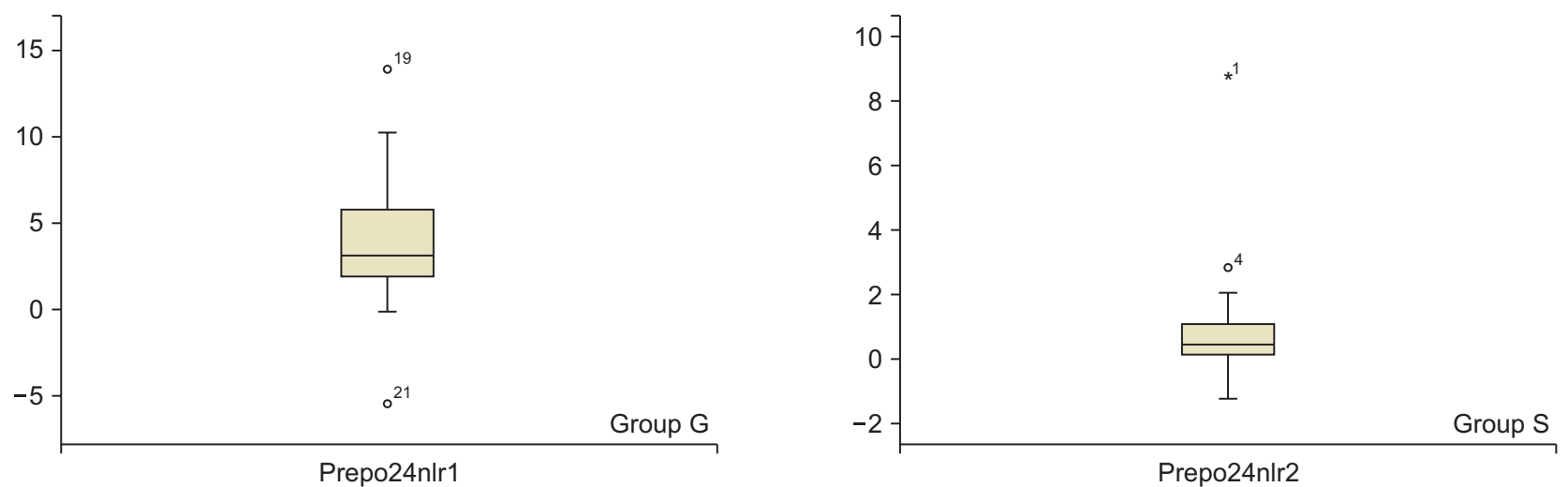

Fig. 3. (A) Difference in NLR at $2 \mathrm{~h}$ from the baseline value in group $\mathrm{G}$ and group S. (B) Difference in NLR at $24 \mathrm{~h}$ from the baseline value in group $\mathrm{G}$ and group S. NLR: neutrophil to lymphocyte ratio. 

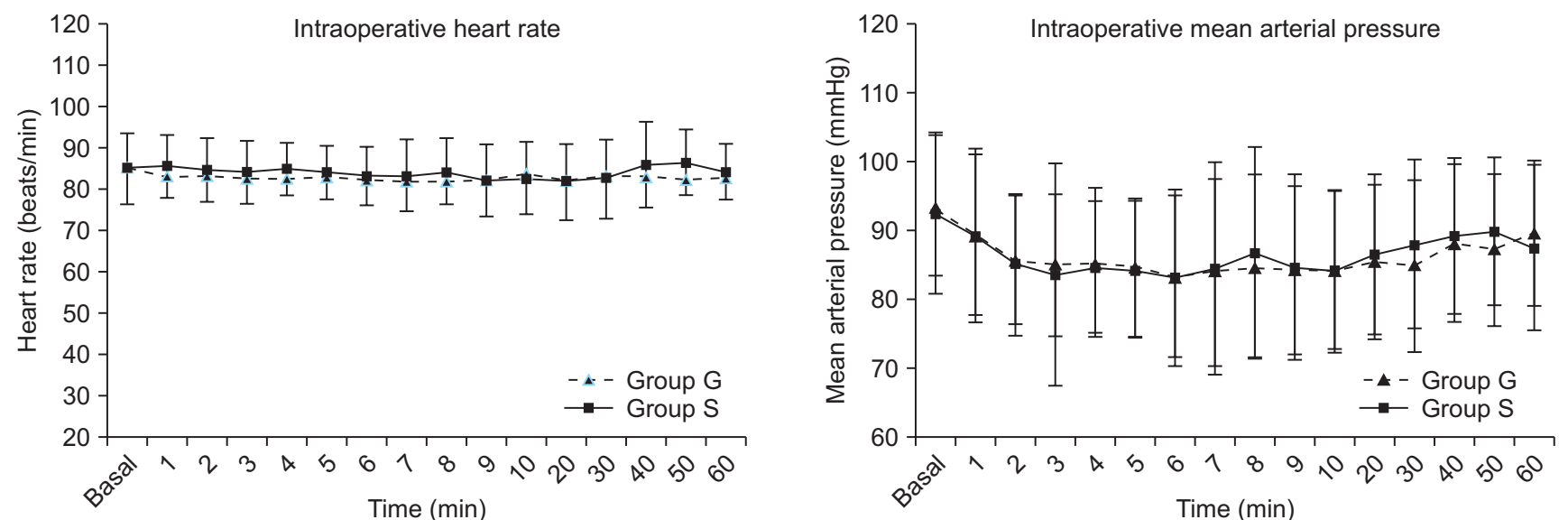

Fig. 5. Comparison of intraoperative heart rate (HR) and mean arterial pressure (MAP) between the two groups.

$(\mathrm{P}<0.001)$ at $24 \mathrm{~h}$ in group $\mathrm{G}$, whereas in group $\mathrm{S}$, these were $0.2 \%(0.12 \%-0.85 \%)(\mathrm{P}<0.001)$ at $2 \mathrm{~h}$ and $0.3 \%(0.24 \%-0.85 \%)$ $(\mathrm{P}<0.001)$ at $24 \mathrm{~h}$. These changes were statistically significant, although not clinically significant. An intergroup comparison of the change in hemoglobin level did not show significant difference ( $2 \mathrm{~h}, \mathrm{P}=0.37 ; 24 \mathrm{~h}, \mathrm{P}=0.36$ ). There was no significant difference in the heart rate and mean arterial pressure between the two groups during the intraoperative period (Figs. 5A and 5B). The mean volume of intravenous fluids administered was $940 \pm 241.57 \mathrm{ml}$ in group $\mathrm{G}$ and $1042.5 \pm 227.45 \mathrm{ml}$ in group $\mathrm{S}(\mathrm{P}$ $=0.054)$.

\section{Discussion}

In the present study, it was observed that spinal anesthesia was associated with a significantly lower NLR and a lower TLC as compared to that after general anesthesia. Studies on surgical trauma-induced stress have reported suppression of cellular resistance and susceptibility to inflammation. In addition, an increase in TLC and a reduction in the lymphocyte count in the post-operative period can increase the chance of infection [12]. These changes in leukocytes have been proposed to release inflammatory cytokines similar to IL-6. Studies have shown that changes in TLC and leukocyte subtypes are important markers of morbidity and mortality in patients with cancer, renal failure, and cardiovascular disorders $[5,13,14]$.

Volatile anesthetic agents have been found to modulate both pro- and anti-inflammatory mediators, thereby resulting in lower lymphocyte counts $[15,16]$. The decreased neuroendocrine response to surgery with regional anesthesia [17] may explain the lesser increase in TLC and NLR in patients receiving spinal anesthesia.

Erbaş et al. [18], in a retrospective study, evaluated the relationship between blood NLR and anesthetic techniques in patients undergoing Cesarean section and concluded that post-operative NLR in these patients after spinal anesthesia was significantly lower as compared to that after general anesthesia, However, to the best of our knowledge, till date, are no other studies reporting the effects of anesthetic technique on NLR in patients undergoing non obstetric surgeries. The results of our study are similar to that of Erbaş et al. [18]. TLC and NLR were significantly lower in Group $S$ as compared to those in Group G postoperatively. Another study found no increase in TLC following spinal anesthesia as compared to that following general anesthesia [19]. In the present study, although the increase in TLC was significant with general anesthesia as compared to that with spinal anesthesia, the magnitude of increase was not high.

A study investigated the effects of two general anesthetic techniques on leukocytic alterations including NLR after gynecologic laparoscopy. A significant increase in TLC, neutrophil count, and reduction in the lymphocyte count were observed at all time points after surgery in patients who received total intravenous anesthesia and who received inhalational anesthesia. NLR was significantly lower in the total intravenous anesthesia group compared to that in the inhalational anesthesia group [20]. A study assessing the correlation between NLR and post-operative complications after major abdominal surgeries found that NLR at day 7 correlated better with the incidence of post-operative complications as compared to other parameters including $\mathrm{C}$ reactive protein. The cut-off level for prediction of post-operative complications was found to be 5.5 [21]. However, another study found that a pre-operative NLR value of $\geq 2.3$ was associated with major post-operative complications in patients undergoing colorectal surgeries [22]. The baseline NLR in the present study was a little higher than that of the mentioned studies. This could be attributed to the probable pre-operative stress as the baseline samples were obtained on the previous day of surgery before administration of the premedications. 
The different types of anesthesia might have indirect effects on the post-operative complications by influencing NLR, and hence, an appropriate choice of anesthesia could influence the final outcomes. However, a study assessing the effects of general and spinal anesthesia on stress response to hemorrhoidectomy found no significant difference related to the effects of general and spinal anesthesia except for an increase in the leptin levels [23]. This could be attributed to the magnitude of surgery. Eight patients included in the study had undergone open-interval appendicectomy. These patients were included in the study as they were symptom-free (a history of acute appendicitis 6 months prior which was managed conservatively) and had no features suggestive of acute infection at the time of surgery. The volume of intravenous fluids administered in Group S was marginally higher than that in Group G. However, this might not have a significant diluent effect on the cell counts.

There are some limitations to the present study. The patients were not followed-up beyond $24 \mathrm{~h}$ for wound site or other infections as the post-operative management was entirely based on the surgical team's protocol over which we had no control. Hence, the relationship between NLR and the incidence of post-operative infections and post-operative outcomes could not be established. However, a retrospective analysis of records found one patient in Group G with urinary tract infection on post-operative day 3 , which improved with antibiotic treatment and there was no delay in the hospital discharge. Other investigations correlating neuroendocrine response with anesthetic technique could not be performed. Further studies are required to assess if a combination of regional anesthesia along with general anesthesia could influence the post-operative outcomes by its effect on NLR as compared to general anesthesia alone. Thus, to conclude, spinal anesthesia was found to be associated with significantly lesser variations in NLR and TLC as compared to that with general anesthesia.

\section{Conflicts of Interest}

No potential conflict of interest relevant to this article was reported.

\section{Author Contributions}

Nethra Surhonne (Conceptualization; Investigation; Methodology; Project administration; Resources; Supervision; Validation; Visualization; Writing-review \& editing)

Chaithali Hebri (Conceptualization; Data curation; Formal analysis; Investigation; Methodology; Resources; Visualization; Writing-original draft)

Sudheesh Kannan (Conceptualization; Formal analysis; Investigation; Methodology; Resources; Software; Validation; Writingreview \& editing)

Devika Rani Duggappa (Conceptualization; Formal analysis; Investigation; Project administration; Resources; Validation; Visualization; Writing-review \& editing)

Raghavendra Rao RS (Conceptualization; Formal analysis; Investigation; Methodology; Project administration; Resources; Supervision; Validation; Writing-review \& editing)

Chethana G Mapari (Data curation; Investigation; Methodology; Resources; Writing-original draft)

\section{ORCID}

Nethra Surhonne, https://orcid.org/0000-0002-5998-2884

Chaithali Hebri, https://orcid.org/0000-0003-0149-7242

Sudheesh Kannan, https://orcid.org/0000-0002-3341-538X

Devika Rani Duggappa, https://orcid.org/0000-0002-3520-0171

Raghavendra Rao RS, https://orcid.org/0000-0003-0203-1444

Chethana G Mapari, https://orcid.org/0000-0002-4963-5280

\section{References}

1. Helmy SA, Wahby MA, El-Nawaway M. The effect of anaesthesia and surgery on plasma cytokine production. Anaesthesia 1999; 54: 733-8.

2. Cruickshank AM, Fraser WD, Burns HJ, Van Damme J, Shenkin A. Response of serum interleukin-6 in patients undergoing elective surgery of varying severity. Clin Sci (Lond) 1990; 79: 161-5.

3. Reith HB, Kaman S, Mittelkötter O, Kilic Y, Kozuschek W. Cytokine activation in patients undergoing open or laparoscopic cholecystectomy. Int Surg 1997; 82: 389-93.

4. Iwase M, Kondo G, Watanabe H, Takaoka S, Uchida M, Ohashi M, et al. Regulation of Fas-mediated apoptosis in neutrophils after surgeryinduced acute inflammation. J Surg Res 2006; 134: 114-23.

5. Ogawa K, Hirai M, Katsube T, Murayama M, Hamaguchi K, Shimakawa T, et al. Suppression of cellular immunity by surgical stress. Surgery 2000; 127: 329-36.

6. Ni Eochagain, A, Burns D, Buggy DJ. Effect of anaesthetic technique during primary breast cancer surgery on neutrophil-lymphocyte ratio, platelet-lymphocyte ratio, and time of commencement of intended oncologic therapy: a follow-up analysis of a prospective randomised trial. Br J Anaeth 2018; 120: e2-3.

7. Papa A, Emdin M, Passino C, Michelassi C, Battaglia D, Cocci F. Predictive value of elevated neutrophil-lymphocyte ratio on cardiac 
mortality in patients with stable coronary artery disease. Clin Chim Acta 2008; 395: 27-31.

8. Forget P, Machiels JP, Coulie PG, Berliere M, Poncelet AJ, Tombal B, et al. Neutrophil:lymphocyte ratio and intraoperative use of ketorolac or diclofenac are prognostic factors in different cohorts of patients undergoing breast, lung, and kidney cancer surgery. Ann Surg Oncol 2013; 20 Suppl 3: S650-60.

9. Alkan M, Erkent FD, Celik A, Gokce A, Arslan M, Unal Y. Effects of thoracic epidural or intravenous analgesia on the neutrophil-tolymphocyte ratio in thoracotomy cases. Niger J Clin Pract 2018; 21: 1337-40.

10. Alexander NI. Reference values of neutrophil-lymphocyte ratio, platelet-lymphocyte ratio and mean platelet volume in healthy adults in north central nigeria. J Blood Lymph 2016; 6: 143.

11. Lee JS, Kim NY, Na SH, Youn YH, Shin CS. Reference values of neutrophil-lymphocyte ratio, lymphocyte-monocyte ratio, plateletlymphocyte ratio, and mean platelet volume in healthy adults in South Korea. Medicine (Baltimore) 2018; 97: e11138.

12. Takahashi J, Shono Y, Hirabayashi H, Kamimura M, Nakagawa H, Ebara S, et al. Usefulness of white blood cell differential for early diagnosis of surgical wound infection following spinal instrumentation surgery. Spine (Phila Pa 1976) 2006; 31: 1020-5.

13. Kim WH, Jin HS, Ko JS, Hahm TS, Lee SM, Cho HS, et al. The effect of anesthetic techniques on neutrophil-to-lymphocyte ratio after laparoscopy-assisted vaginal hysterectomy. Acta Anaesthesiol Taiwan 2011; 49: 83-7.

14. Forget P, De Kock M. Perspectives in anaesthesia for cancer surgery. J Cancer Res Clin Oncol 2014; 140: 353-9.

15. Stollings LM, Jia LJ, Tang P, Dou H, Lu B, Xu Y. Immune modulation by volatile anesthetics. Anesthesiology 2016; 125: 399-411.

16. Schneemilch CE, Ittenson A, Ansorge S, Hachenberg T, Bank U. Effect of 2 anesthetic techniques on the postoperative proinflammatory and anti-inflammatory cytokine response and cellular immune function to minor surgery. J Clin Anesth 2005; 17: 517-27.

17. Milosavljevic SB, Pavlovic AP, Trpkovic SV, IlićAN, Sekulic AD. Influence of spinal and general anesthesia on the metabolic, hormonal, and hemodynamic response in elective surgical patients. Med Sci Monit 2014; 20: 1833-40.

18. ErbaşM, Toman H, Gencer M, Şahin H, Kiraz HA, Şimşek T, et al. The effect of general and spinal anesthesia on neutrophil to lymphocyte ratio in patients undergoing cesarian section. Anaesth Pain Intensive Care 2015; 19: 485-8.

19. Kim MH, Lim KI. The influence of anesthetic technique on the responses of white blood cells and interleukin- 6 in patients undergoing low abdominal surgery. Korean J Anesthesiol 2000; 39: 177-82.

20. Kim WH, Jin HS, Ko JS, Hahm TS, Lee SM, Cho HS, et al. The effect of anesthetic techniques on neutrophil-to-lymphocyte ratio after laparoscopy-assisted vaginal hysterectomy. Acta Anaesthesiol Taiwan 2011; 49: 83-7.

21. Forget P, Dinant V, De Kock M. Is the Neutrophil-to-Lymphocyte Ratio more correlated than C-reactive protein with postoperative complications after major abdominal surgery? PeerJ 2015; 3: e713.

22. Josse JM, Cleghorn MC, Ramji KM, Jiang H, Elnahas A, Jackson TD, et al. The neutrophil-to-lymphocyte ratio predicts major perioperative complications in patients undergoing colorectal surgery. Colorectal Dis 2016; 18: O236-42.

23. Buyukkocak U, Caglayan O, Daphan C, Aydinuraz K, Saygun O, Agalar F. Similar effects of general and spinal anaesthesia on perioperative stress response in patients undergoing haemorrhoidectomy. Mediators Inflamm 2006; 2006: 97257. 